\title{
An Approach to Grade Aggregates having Mild Potential Alkali - Silica Reactivity
}

\section{C.K. Pathirana, H. Abeyruwan, H.M.G.T.A Pitawala and A.P.N. Somaratna}

\begin{abstract}
In many parts of the world concrete structures have failed due to Alkali-Aggregate Reaction (AAR). Researchers have explored remedial actions to be taken and mitigation techniques to be followed in concrete construction to alleviate the problem of AAR. In Sri Lanka, so far no documented evidence has been produced about investigations of this nature though there are a few old concrete structures which are still being used but showing symptoms similar in nature to AAR. To investigate the potential alkali-silica reactivity of Sri Lankan aggregates, preliminary work has been attempted. A quick chemical method which is used in many countries has been used to test fine and coarse aggregates collected from different locations in the country. According to the results, many aggregates can be placed in the non-reactive zone of the chart of innocuous and deleterious aggregates illustration of ASTM C 289. But some fall in a gray area close to the boundary of the demarcation of reactivity, which could be defined as a 'slowly reactive' zone. Having recognized the significance of quantifying the degree of reactivity of such slowly reactive aggregates, a new parameter called 'potential reactivity index' has been introduced. This index may serve the process of screening aggregates for structures of long life expectancies.
\end{abstract}

Keywords: Alkali-Aggregate Reaction, slowly reactive aggregates, potential reactivity index

\section{Introduction}

Concrete has become a widely used construction material all over the world. One of the major causes of serviceability and durability problems of concrete structures is the Alkali-Aggregate Reaction (AAR), which can lead to premature cracking and distortion of the structures. In general terms it is a reaction between aggregates and the alkalis in the pore water in cement paste. Literature [1, 2 , 3] has shown that AAR can be separated into two main categories according to the active mineral component of the aggregate which is involved in the reaction. When this active mineral component is silica, the reaction is called Alkali-Silica Reaction (ASR) and when it is carbonates, the reaction is called Alkali-Carbonate Reaction (ACR). According to the literature $[2,3], \mathrm{ASR}$ is more common than ACR. All aggregates containing silica or carbonates are not equally susceptible to AAR. In the early 1940's, the first evidence of AAR was reported by Stanton [4] as formation of cracks in some concrete pavements in California, USA. The cause of these cracks had been identified as the formation of a gel layer due to high alkali cements and some mineral phases in certain types of aggregates. With the absorption of water, this layer of gel expands. As a result there may be expansion, cracking, increased permeability, and decreased modulus and tensile capacity of concrete [5]. However cement is not always the only source of the alkalis involved in the deleterious reactions. Deleterious alkalis may come from groundwater, seawater, deicing chemicals, or other sources (eg. aggregates) [6]. The identification of AAR as a cause of concrete deterioration needs an integration of field and laboratory evidence. It is highly complicated and costly to contain the reaction once it starts. There are various engineering standards for the ingredients to meet before being used in concrete construction. Screening of reactive aggregates is an appropriate method of avoiding long-term problems of AAR.

Special attention must be paid to aggregates as the performance characteristics in the durability of the structure depend on their mineralogy and texture.

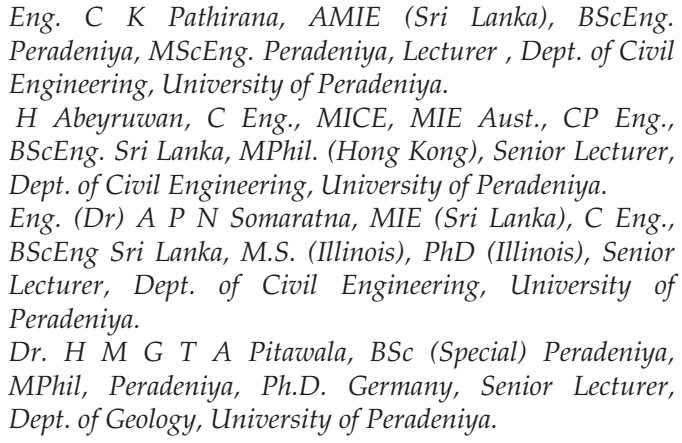

Eng. C K Pathirana, AMIE (Sri Lanka), BScEng. Peradeniya, MScEng. Peradeniya, Lecturer, Dept. of Civil Engineering, University of Peradeniya.

H Abeyruwan, C Eng., MICE, MIE Aust., CP Eng., BScEng. Sri Lanka, MPhil. (Hong Kong), Senior Lecturer, Dept. of Civil Engineering, University of Peradeniya. Eng. (Dr) A P N Somaratna, MIE (Sri Lanka), C Eng., BScEng Sri Lanka, M.S. (Illinois), PhD (Illinois), Senior Lecturer, Dept. of Civil Engineering, University of Peradeniya.

Dr. H M G T A Pitawala, BSc (Special) Peradeniya, MPhil, Peradeniya, Ph.D. Germany, Senior Lecturer, Dept. of Geology, University of Peradeniya. 
To investigate the potential alkali-silica reactivity of aggregates, the American Society for Testing and Materials (ASTM) C 289 method,

a rapid chemical test, has been widely used all over the world. The aggregates are categorized

as deleterious, potentially deleterious and innocuous by this standard test. In literature, it has been reported that in some cases though the aggregates were classed as non-reactive or uncertain by standard methods, the structures made out of such aggregates had shown the effects of AAR $[7,8]$. Over the past seventy years, many researchers [ $1-5]$ have carried out a fair amount of work on this subject. Some have indicated that the current standard test methods used are not stringent enough to identify certain levels of the reactivity [8].

In Sri Lanka too, there are large concrete structures such as dams about 20 years old. Those may also be susceptible to AAR though no such complications have been documented yet. The objective of this study is to propose a test method and graded reactivity level for identification of reactive aggregates in Sri Lanka.

Several samples of aggregates were collected from a few locations in the country and tests were carried out to determine the reactivity level. In compliance with ASTM C 295, petrographic examination of aggregates was also performed to identify any reactive components of aggregates which could induce expansive alkali-aggregate reaction.

\section{Sample collection and Method of Study}

Locations of samples were selected randomly in the region shown in Figure 3 for initiation of the research study. Samples of coarse aggregates and fine aggregates were collected from active quarries in Gampola, Peradeniya, Kothmale, Rikillagaskada, Mahiyangana, Thalawakele, Nuwaraeliya, Padukka, Horana, Aladeniya, Kaduwela, Watagoda, Nillambe, Welioya, Sarasavigama, Haragama, Dambadeniya and Oluvil.

Further investigations will also be carried out in order to identify the supply chain of the aggregates to construction sites. This will provide us a meaningful strategy to investigate for AAR the structures built with such aggregates.

\section{Experimental Procedure}

The standard test ASTM C $289-07$ [9] was the basis of this study. This test method covers chemical determination of the potential reactivity of an aggregate with alkalies and it is fairly quick. Using this test, the potential alkali-silica reactivity of these aggregates was investigated.

Thin sections were also prepared from aggregate samples for the petrographic examination according to ASTM C 295 - 08 [10].

\subsection{Preparation of test samples}

\subsubsection{Reaction samples}

$300 \mathrm{~g}$ sample was sieved through a set of sieves ranging from aperture size $300 \mu \mathrm{m}$ to $150 \mu \mathrm{m}$, discarding all material that passes the $150 \mu \mathrm{m}$ sieve. Then the sample (in small portions) was crushed and ground using a disk pulverizer, mortar and pestle. Grinding was continued until the amount of material passing through the $300 \mu \mathrm{m}$ sieve and remaining on the $150 \mu \mathrm{m}$ sieve was about 110 to $150 \mathrm{~g}$. To ensure that all material finer than the $150 \mu \mathrm{m}$ sieve has been removed, the sample was washed over a $150 \mu \mathrm{m}$ sieve. The portion retained on the $150 \mu \mathrm{m}$ sieve was taken as the test sample.

\subsubsection{Mineralogical studies}

$50 \mu \mathrm{m}$ thick slices were cut from the aggregate samples and thin sections were prepared from them at the Department of Geology, University of Peradeniya. Samples of fine aggregates were mounted on glass slides. Primary and secondary minerals in the samples were identified using optical microscopes.

\subsection{Methodology}

\subsubsection{Reactivity test}

Three representative $25.00 \pm 0.05$ g portions of a test sample were weighed. Each portion was placed in three stainless steel reaction containers and $25 \mathrm{ml}$ of $1.000 \mathrm{~N} \mathrm{NaOH}$ solution was added to each by means of a pipet. $25 \mathrm{ml}$ of the same $\mathrm{NaOH}$ solution was poured into a fourth reaction container to serve as a blank. Following the procedure given in ASTM C 289 - 07, filtrates were prepared. Then a diluted solution was 
prepared from the filtrate to determine the dissolved silica and the reduction in alkalinity. In this study, the gravimetric method was selected to measure dissolved silica. Using titrations with $0.05 \mathrm{~N} \mathrm{HCl}$ to the phenolphthalein end point, reduction in alkalinity was calculated. The same procedure was followed for all the aggregate samples.

\section{Experimental Results}

\subsection{Reactivity Tests}

Table 1 shows the values obtained for dissolved silica, $S_{c}$, and the reduction in alkalinity, $R_{c}$, for tested samples. According to ASTM C 289 the determination of reactivity is made by considering the location of each sample on a plot of reduction in alkalinity vs. dissolved silica. Figure 1 shows the three zones in the plot. However it is felt that it is unrealistic to expect sharp boundaries among the zones. In this study new parameters are proposed to take into account the gradual transition between zone 1 and zone $2 / 3$. The minimum distance from a position within zone 1 in the plot to the zone boundary has been named as the 'potential inertness index', $d$, estimated in natural scale and not in log scale (see Figure 1). The 'potential reactivity index' (PRI) has been defined as follows.

$$
P R I=100 /(1+d)
$$

This new concept is proposed to quantify the potential reactivity of the materials which are categorized as innocuous according to the current standard tests but marginally reactive. PRI is defined in such manner that when $d$ equals zero the index becomes $100 \%$ and the material belongs to reactive category. As $d$ increases the index becomes smaller which means that the material has a lower relative potential reactivity.

Both these parameters were estimated for each sample in this study (Table 1).

Figure 2 shows the potential reactivity of samples tested according to the standard test ASTM C 289 and Table 1 lists their Potential Reactivity Indices. Figure 3 shows their geographic distribution.

Quantity $S_{c} /($ millimoles / litre) [log scale]

\author{
Zone 1 - Innocuous \\ Zone 2 - Potentially deleterious \\ Zone 3 - Deleterious \\ $\mathrm{R}_{\mathrm{c}}-$ Reduction in alkalinity \\ $\mathrm{S}_{\mathrm{c}}$ - Dissolved silica
}

Figure 1 - Illustration of Potential inertness index of a sample aggregate 


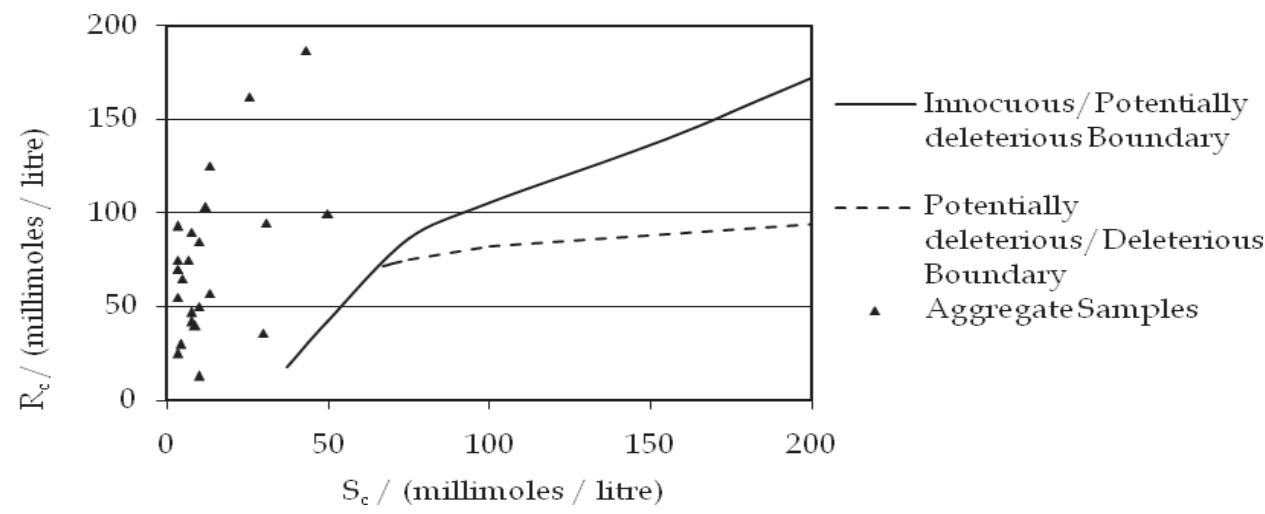

Figure 2 - Potential Reactivity levels of samples according to ASTM C 289

Table 1 - Reduction in alkalinity and dissolved silica for aggregate from different locations

\begin{tabular}{|c|c|c|c|c|c|}
\hline \multirow[t]{2}{*}{ Location } & \multicolumn{2}{|c|}{$\begin{array}{l}\text { Reduction in alkalinity, } \\
\mathrm{R}_{\mathrm{c}} / \text { (millimoles / litre) }\end{array}$} & \multirow{2}{*}{$\begin{array}{c}\text { Dissolved } \\
\text { silica, } \mathrm{S}_{\mathrm{c}} / \\
\text { (millimoles / } \\
\text { litre) }\end{array}$} & \multirow{2}{*}{$\begin{array}{c}\text { Potential } \\
\text { Inertness } \\
\text { Index } 1 \\
\text { ' } d \text { ' } \\
\text { (millimoles / } \\
\text { litre) }\end{array}$} & \multirow{2}{*}{$\begin{array}{c}\text { Potential } \\
\text { Reactivity } \\
\text { Index (PRI) } \\
\%\end{array}$} \\
\hline & $\begin{array}{l}\text { Crushed } \\
\text { rock }\end{array}$ & $\begin{array}{l}\text { Natural } \\
\text { uncrushed } \\
\text { sand }\end{array}$ & & & \\
\hline Gampola & 65 & & 5.00 & 50.0 & 1.96 \\
\hline Kaduwela & 25 & & 3.33 & 39.6 & 2.46 \\
\hline $\begin{array}{l}\text { Thalawakele } \\
\text { (tunnel muck) }\end{array}$ & 55 & & 3.33 & 48.1 & 2.04 \\
\hline Watagoda & 75 & & 3.33 & 55.3 & 1.78 \\
\hline $\begin{array}{l}\text { Kothmale } \\
\text { (switchyard) }\end{array}$ & 125 & & 13.32 & 72.0 & 1.37 \\
\hline Rikillagaskada & 93 & & 3.33 & 63.1 & 1.56 \\
\hline Nillambe & 50 & & 10.00 & 40.2 & 2.43 \\
\hline Thalawakele & 187 & & 43.30 & 97.4 & 1.02 \\
\hline Padukka & 40 & & 8.88 & 38.2 & 2.55 \\
\hline Horana & 42 & & 7.77 & 39.9 & 2.44 \\
\hline Welioya & 70 & & 3.33 & 53.4 & 1.84 \\
\hline Niyangamdora & 70 & & 3.33 & 53.4 & 1.84 \\
\hline Galaha & 90 & & 7.66 & 57.9 & 1.70 \\
\hline Sarasavigama & 47 & & 7.75 & 41.4 & 2.36 \\
\hline Dambadeniya & 75 & & 6.66 & 52.3 & 1.88 \\
\hline Aladeniya & 30 & & 4.44 & 39.8 & 2.45 \\
\hline Haragama & 36 & & 30.00 & 16.8 & 5.62 \\
\hline Kothmale & & 162 & 25.50 & 88.5 & 1.12 \\
\hline Oluvil & & 13 & 9.99 & 30.4 & 3.18 \\
\hline Nuwara Eliya & & 57 & 13.50 & 39.2 & 2.49 \\
\hline Mahiyangana & & 103 & 12.20 & 60.3 & 1.63 \\
\hline Peradeniya & & 95 & 30.80 & 40.3 & 2.42 \\
\hline
\end{tabular}

1 ' $d$ ' is in natural scale. 


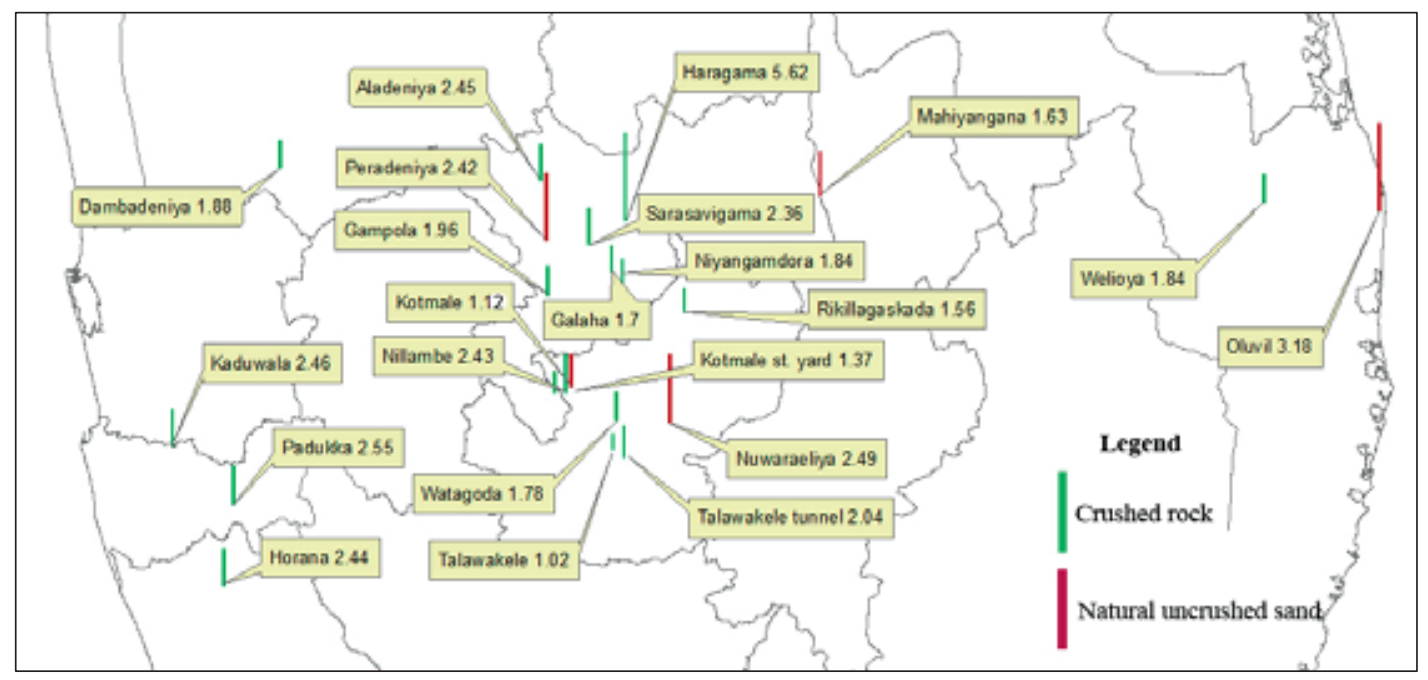

Figure 3 - Potential Reactivity Index of aggregates and their locations

Table 2 - Summary of petrographic studies

\begin{tabular}{lll}
\hline $\begin{array}{l}\text { Sample No. } \\
\text { S-5 } \\
\text { from } \\
\text { Haragama }\end{array}$ & Texture & Angular grains \\
\cline { 2 - 3 } & Mineralogy & Quartz, feldspar and biotite \\
\cline { 2 - 3 } $\begin{array}{l}\text { Secondary } \\
\text { S-7 }\end{array}$ & $\begin{array}{l}\text { Moth amorahous and crystalline bladed phases are present. Micro } \\
\text { crystalline products along the fractures and the cleavages of } \\
\text { minerals were identified. }\end{array}$ \\
\cline { 2 - 3 } From Galaha & Texture & Fine to medium grained angular particles. \\
\cline { 2 - 3 } & Mineralogy & Quartz and opaque minerals \\
\cline { 2 - 3 } & Secondary & $\begin{array}{l}\text { Alterations are present. Micro-crystalline materials are also present } \\
\text { in cracks that intersect each other. However, the intensity of the } \\
\text { alteration is not considerable. Some voids of grains were filled by } \\
\text { secondary iron products. }\end{array}$ \\
\hline $\begin{array}{l}\text { Sample No. } \\
\text { S-8 }\end{array}$ & Texture & Angular coarse to medium grained. \\
\cline { 2 - 3 } $\begin{array}{l}\text { From } \\
\text { Sarasavigama }\end{array}$ & Mineralogy & $\begin{array}{l}\text { Most of grains are fresh (90 percent) quartz, garnet, iron oxide } \\
\text { minerals (magnetite and ilmenite) and biotite. }\end{array}$ \\
\cline { 2 - 3 } & Secondary & $\begin{array}{l}\text { Alteration of biotite into muscovite is present. Weakly developed } \\
\text { recrystallizations along fractures of quartz grains are found from } \\
\text { few grains. The cracks of most of grains are lacking of secondary } \\
\text { mineralization. }\end{array}$ \\
\hline
\end{tabular}

\subsection{Petrography}

Petrographic studies revealed the presence of both stable minerals and unstable minerals in aggregates. They can also be used to identify some secondary minerals (altered minerals) which may have formed by chemical reactions developed under natural conditions. The textural and mineralogical characteristics of aggregates can be used to recognize any deleterious components present and to classify them. Generally, the natural silica constituents such as opal, chalcedony, quartz, cristobalite, tridymite, chert are considered to be potentially reactive [8]. Table 2 summarizes the results of petrographic examination of some of the samples.

\section{Discussion}

The phenomenon of ASR is complex, and there are many interacting and interdependent parameters that influence its occurrence. Many countries have experienced ASR which results in unpredictable and uncontrollable effects on concrete structures. Therefore, it is very important to assess and evaluate the potential 
reactivity of aggregates prior to their use in concrete construction.

The structure and texture of siliceous fractions are generally described in terms such as amorphous, cryptocrystalline, microcrystalline and crystalline. Silica $\left(\mathrm{SiO}_{2}\right)$ itself occurs in a number of polymorphic forms. The most common form of silica minerals includes quartz, tridymite, cristobalite, opal and chalcedony group, which covers a number of varieties of silica, composed of minute crystals of quartz with submicroscopic pores.

Microscopic investigations indicated that almost all studied aggregates have primarily (fresh) quartz as major mineral constituent with angular texture. However some samples collected from Haragama are characterized by amorphous phases developed recently. This is of vital importance in recognizing the susceptibility of potential reactivity as many reactive aggregates contain amorphous phases according to previous studies [7].

Results of the alkali-reactivity tests for aggregate samples have been shown in Table 1. Though the results of ASTM C 289 test for all samples fall in the region of 'innocuous', it may not be treated as a definitive criterion for acceptance of an aggregate to be used in concrete structures of long service life expectancy, as slowly reactive aggregates might escape detection [7]. In the case of a sample falling close to the innocuous/deleterious boundary the potential reactivity value (PRI) may give some indication of reactivity. The higher the potential reactivity index, the closer the sample is to the zone of potentially deleterious or deleterious zone. With the continuation of data a gray area close to the boundary of the demarcation of reactivity could be defined as a 'slowly reactive zone'. Table 2 shows that Haragama sample has an index of 5.62 which is very close to the boundary of zone 3 where aggregates are considered deleterious. Even though there is a possibility of determining the potential reactivity of an aggregate by petrographic examination, it does not give any measure of the degree of reactivity, and there should be some ancillary testing to confirm it.

\section{Acknowledgement}

Financial support provided by UGC grant No. UGC/ICD/RPC/015 to the first author and NSF grant No. RG/2007/E/06 to the fourth author is gratefully acknowledged.

\section{References}

1. ACI Committee 221, State-of-the-Art Report on Alkali-aggregate Reactivity (221.1R-98), American Concrete Institute, Farmington Hills, Michigan, USA, pp.1-31, 1998.

2. Xiangyin Mo, ChenjienYu and Zhongzi Xu, Long-term Effectiveness and Mechanism of $\mathrm{LiOH}$ in inhibiting Alkali-Silica Reaction, Cement and Concrete Research, 33, pp. 115-119, 2003.

3. Xiangyin Mo, Tongshun Jin, Gang Li, Keyu Wang, Zhongzi $\mathrm{Xu}$ and Mingsho Tang, Alkali-Aggregate Reaction suppressed by Chemical Admixture at $80^{\circ} \mathrm{C}$, Construction and Building Materials, 19, pp. 473-479, 2005.

4. Stanton, T. E., Expansion of Concrete through Reaction between Cement and Aggregate, ASCE Proceedings, 66, No.10, pp. 1781-1811, 1940.

5. Chen, J., Jayapalan, A. R., Kim, J. Y., Kurtis, K. E. and Jacobs, L. J., Nonlinear Wave Modulation Spectroscopy Method for UltraAccelerated Alkali-Silica Reaction Assessment, ACI Materials Journal, pp. 340-348, July August, 2009.

6. FHWA-HRT-04-150, Petrographic methods of examining hardened concrete: A petrographic manual, Virginia Transportation Research Council, VA, 2004, pp. 155-179.

7. Shayan, A. and Quick, G. W., Microscopic Features of Cracked and Uncracked Concrete Railway Sleepers, ACI Materials Journal, pp.348-361, July - August, 1992.

8. Swamy, R. N., The Alkali-Silica Reaction in Concrete, Blackie and sons Ltd., Glasgow and London, 1992, Ch. 3.

9. American Society for Testing Materials, ASTM C 289 - 07, Annual Book of ASTM Standards, Concrete and Aggregates, Vol. 04.02, pp. 179-185, 2009.

10. American Society for Testing Materials, ASTM C 295 - 08, Annual Book of ASTM Standards, Concrete and Aggregates, Vol. 04.02, pp.199-206, 2009. 